\title{
Electronic and Information Engineering Practice Teaching Reform
}

\author{
Baiqing $\mathrm{He}^{1}$, Zimin Wang ${ }^{2}$
}

\section{Nanchang institute of technology, Nanchang330044, China; \\ 86035262@qq.com,308809980@qq.Com.}

Keywords: teaching programs; Electronic and Information Engineering; engineering education; CDIO;

\begin{abstract}
For Electronic and Information Engineering, the education reform over the years and always stay in the textbook, reform a new name.Especially in the undergraduate level inside the private institutions of higher learning, simply continue to use the previous teaching idea to simply meet the demands of the new curriculum, students scanty theory, let alone innovation or applied.These innovative applications can not meet society's demand for talents.
\end{abstract}

In order to adapt to the culture of modernization talents of applied technology, will CDIO teaching philosophy and existing existing training program together. Clear training objectives, the implementation of personnel training programs to improve the professional skills of personnel; from theory to training, from training to the project, follow through gradual expansion of the teaching content, teaching reform program to enhance students' professional qualities.

The rapid development of electronic technology, knowledge has become increasingly diverse, the structure becomes larger, the face of the supply-side reform and development strategy of the central government, various e-business for innovative talents and practical talents requirements are increasingly high, It requires that higher education must be able to keep pace with the times.For the purposes of Chinese colleges and universities, such as "985" and "211" key universities such, responsible for the important task of national culture of line personnel and academic talents, education has a relatively abundant funds, personnel location is also very clear.But most local colleges and universities lack the appropriate educational resources, but want to go the path of key institutions, the result is neither cultivate research talent, nor cultivate practice-based talent. This is the Development of Universities positioning is not clear, so that no explore a training program for their own development caused embarrassment.

\section{First, electronic information teaching background}

Education has always been scholars continue to study the issue, but only cultivate students' creative and practical ability of the results, the foreign education clearly ahead in the domestic higher education.In recent years, with the development of market economy, domestic short board further highlight education, more and more college graduates exhibit the phenomenon of social maladjustment actual production, more and more enterprises to the beginning of the university graduates and also to avoid much of.How to promote higher education professional, socially-oriented production, is also troubled by a problem of education scholars. Last year, Vice Minister of Education Lu Xin introduction, China now has nearly 2,500 colleges and universities, will drive more than 1,700 schools in 1600 to gradually shift to vocational and technical education;Meanwhile, in the training mode, these universities will fade discipline, strengthen professional and cultivate innovative application of talent.This is also the trend of the times. And for Electronic and Information Engineering, the education reform over the years and always stay in the textbook, reform a new name. 


\section{Second, Electronic and Information Engineering Practice Teaching Reform significance}

(1)improve teachers' practical ability to improve the level of professional counseling teachers to encourage teachers to vigorously carry out basic scientific research, to promote the "Double" teachers construction.

(2)equilibrium theory lessons and the ratio between the experimental class, increase efforts to develop students practical ability, so that students basic theoretical knowledge through experimental teaching confirmatory further understand and digest learned.

(3)attempts to open training project teaching as the main content of the curriculum, students are encouraged to customize the hands-on design projects to improve students' knowledge of the innovative application capabilities.

(4)implementation of knowledge "there is a carry out there" to ensure that students learn knowledge and can be used for the society and promoting vocational education reform and development progress, cultivating new innovation talents.

\section{Third, the Nanchang Institute of Electronic and Information Engineering Excellence in Teaching Team}

Nanchang Institute of Electronic and Information Engineering school departments approved the establishment of focus.Today, Electronic and Information Engineering for the provincial specialty construction projects, Electronic and Information Engineering teaching team for the provincial teaching team, electrical and electronic experiment center for the provincial experimental demonstration center of universities.Electronic and Information Engineering teaching team in the original training program on the build philosophy CDIO engineering education in order to achieve the theory with practice, Engineering Teaching normalization teaching effect, the ultimate goal of achieving effective practical teaching reform, improve students' professional skills, to develop practice-based professionals, science and education Gan contribute.

\section{Four, CDIO teaching philosophy Reform}

CDIO( Conceive、Design 、Implement 、Operate ) Teaching philosophy mainly refers to engineering education, the core idea of including two aspects: a target, an outline.CDIO goal is to use modern electronic enterprise production environment, with real engineering projects for the training means, by the amount of real time training to training to master profound theoretical knowledge and skilled hands of professional practice skills talents.CDIO outline the modern electronics industry mainstream technology requires modern electronic engineers and electronics knowledge and skills refined single expression, the formation of specific, quantifiable assessment system for teaching teachers and students have guiding significance. In fact, the core idea of Electronic and Information Engineering Practice Teaching Reform is to develop graduates with a practical hands-on ability, which is the modern society, especially the supply and demand side of the big reform environment.

\section{Fifth, Electronic and Information Engineering Personnel Training Orientation and called} for reform

Universities carry out the teaching process is based on training model, to train how kind of talent, by the way how to develop, are teaching workers should think about.Scientific and practical talent training mode, allow students to build knowledge, ability and professionalism, which is teaching 
every worker most willing to see the results.After all, personnel training on the one hand determines how to achieve teaching objectives and specifications, namely the culture of research and practice-based professionals, on the other hand teaching of teaching in order to achieve such a purpose, to be taken and teaching methods important issues of teaching operational mechanism are Electronics and information Engineering professional Training model in need to think about.

\section{(A) Personnel training target.}

Location of training objectives is reflected in the school's teaching philosophy.Nanchang Institute of Technology teaching philosophy is: 'Thought good, solid foundation, broad knowledge, strong learning ability, practical ability and creative spirit, a healthy personality of high-quality applied talents.Specifically, Electronic and Information Engineering students to be cultured for the service industry talents.Contemporary society, the supply-side reform is imperative, how did recommend in the coming years effective supply-side reform performance, but also need a number of practical ability and innovative applied talents.Nanchang Institute of Technology is conscious of its teaching characteristics, not the blind pursuit of theory-based talent, but the combination of experience and trends in the development of regional industrial development of their own for many years, focusing on the culture of technology-based, practice-based talent.In 2016 graduates, for example, more than $90 \%$ are engaged in the professional work in the electronics industry, and even some college graduates Training College after practice to master a more excellent professional knowledge, have entered the world stage in the junior 500 Huawei company internship, these outstanding students outside the school is pride, practical training in the school experience is that they can travel to protect the workplace.There are a number of graduates into the company Nanchang Ophelia light work in technical jobs demonstrated their professional skills and achievements are obtained colleagues and leaders affirmed.

\section{(B) The requirements of talent training objectives.}

Requires training objectives is used in teaching and teaching methods teaching operation mechanism.Nanchang Institute of Technology attaches great importance to the training of students on courses.Electronic and Information Engineering has specialized academic leaders led Arrangement practice teaching courses. Teaching of theory and practice teaching parallel teaching methods, based on the original talent training plan, to raise the proportion of practice teaching, highlighting the importance and practice of teaching reform of urgency.On the other hand, in order to guarantee the normal operation of the daily practice of teaching, instructing College Experimental Center is responsible for logistical support.

1, Guarantee unimpeded use training room.Institute of Experimental Center must arrange for the training room equipment inspections and maintenance, if found to have a training room equipment appeared circumstances beyond normal operation, and maintenance must be promptly reportedOn the other hand, experimental center but also to ensure a high degree of openness of the training room, allowing students to practice in a non-working hours training on their own.

2, Guarantee supplies of complete intact.Electronic and Information Engineering Training Course is a consuming process of electronic components, students design the circuit, welding circuit board is required to use a soldering iron, solder wire, electronic components and other supplies, a shortage of elements can not appear the case to protect the course continuity and integrity. 


\section{Sixth, Electronic and Information Engineering Teaching Plan Reform}

One focus of the reform of professional electronic information engineering is the lesson plans of reform.The so-called lesson plans that teachers preaching Tuition basis.Over the years, the teaching profession is theory-based, confirmatory experimental supplement.The Nanchang Institute of Technology saw the drawbacks of this teaching method, drastic reform, the first ax is Kanxiang teacher lesson plans.Former teacher lesson plans are great article introduces theoretical knowledge, and later Electronic Information Engineering teaching team is also studying how to improve students 'practical ability, after discussion agreed that, to improve students' practical ability, we must let students in the usual course of study often have the opportunity to do it. So now the lesson plan is no longer in the book exactly the theoretical knowledge, but includes a hands-on practical circuit design.

Practical Teaching Reform of Electronic Information Engineering is to determine the curriculum and teaching programs Electronic and Information Engineering covers every semester courses, hours and credits, including lessons and content of Practice Course.

(1) To determine the appropriate proportion of experimental teaching.

The book brought training room, training with books to verify and explain the principles, theorems, deepen the understanding of theoretical knowledge.

(2) Determine the appropriate open training programs.Now let the students themselves to literature, to design the composition of the project, to verify the feasibility of the project, and finally make real electronic products.Through training programs to stimulate students' imagination and exploration of self-learning ability.

\section{References}

[1] Yu WenJing.On Teachers' classroom learning ability [J]. Exploring education development. 2015(Z2)

[2] Xiaoming Ming. Construction of Electronic Information Engineering Specialty cultivate excellent engineers [J].Wuhan University earned journal (Natural Science Edition). 1 2012(S2) 